\title{
Processos de mudança climática durante a "Pequena Idade do Gelo" sob o enfoque de Ciência do Sistema Terra
}

\section{Climate change processes during the “Little Ice Age" from the perspective of Earth System SCIence}

\author{
Celso Dal Ré Carneiro ${ }^{1}$, Lucca Martins Franco², Gabriel Bueno Fagundes de Freitas², Pedro Wagner Gonçalves ${ }^{3}$ \\ 1 - Programa de Pós-Graduação em Ensino e História de Ciências da Terra, Pesquisador do CNPQ, Instituto de Geociências, Universidade Estadual de Campinas, \\ CAMPINAS, SP, BRASLL. \\ 2 - Instituto de Geociências, Universidade Estadual de Campinas, Graduando em Geologia. Campinas, SP, Brasil. \\ 3 - Programa de Pós-Graduação em Ensino e História de Clências da Terra, Instituto de Geociências, Universidade Estadual de Campinas, Campinas, SP, Brasil.

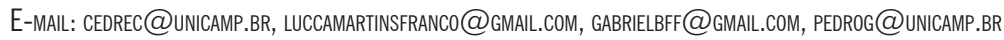

Abstract: There are uncertainties about the exact duration of the "Little Ice Age" (LIA), between the $16^{\text {th }}$ and $19^{\text {th }}$ centuries. The intense cooling in different regions of Northern Hemisphere caused some global effects, such as expansion of the polar ice cap, reduction of average Summer temperatures and increase of Winter precipitation. A bibliographical review of the scientific knowledge regarding the LIA allowed the study, from a systemic point-of-view, of the debate about Holocene climate models and interpretations of probable causes. Climatologists currently diverge regarding methods for dating glacial records and on the controlling mechanisms of abrupt climatic changes. Despite that, the study of available models suggested common factors that determine global climate today, allowing the identification of convergences in interpretations on possible causes of the LIA.

\section{Manuscrito:}

Recebido: Artigo selecionado, IX Simpósio Nacional de Ensino e História de Ciências da Terra / EnsinoGE0-2019

Aceito: 07/10/2019

Citação: Carneiro, C. D. R.; Franco, L. M.; Freitas, G. B. F.; Gonçalves, P. W. (2019).. Processos de mudança climática durante a "Pequena Idade do Gelo" sob 0 enfoque de Ciência do Sistema Terra. Terræ Didatica, 15, 1-10, e19043. doi: 10.20396/td.v15i0.8657525

Palavras-chave: Geologia, Holoceno, Glaciação, Geociências, Mudança Climática, Ambiente.

\section{Introdução}

O evento climático conhecido como "Pequena Idade do Gelo" (PIG) envolveu resfriamento intenso de todo o hemisfério norte entre o final da Idade Média e início da Idade Moderna. O intervalo mais aceito é 1550-1850 AD (Jones \& Bradley, 1992, apud Nesje \& Dahl, 2003), mas dados da Escandinávia indicam que a PIG perdurou até aproximadamente 1920 AD. O período descontínuo de alterações climáticas, em escalas de espaço e de tempo, não ocorreu simultaneamente em todo o hemisfério boreal (Nesje \& Dahl, 2003).

A alternância de mudanças climáticas é elemento natural, intrínseco ao equilíbrio dinâmico do Sistema Terra. As teses discutidas analisam vulcanismo e mínimos de atividade solar, explorando evidências e dados de proxy. Simulações climáticas explicam a alteração da precipitação e a resposta térmica nas regiões afetadas pelos mecanismos naturais. Durante a Pequena Idade do Gelo alguns períodos exibiram anomalias térmicas mais acentuadas do que outros, o que explica a falta de consenso quanto a início e duração da PIG. As fases de maior expansão de geleiras e redução das temperaturas nos invernos e verões correspondem a meados dos séculos XIII, XV e XVII e final do século XVIII (Briffa \& Matheus, 2005). Na Europa, o frio intenso provocou queda na produção agrícola, fome, movimentos migratórios e doenças.

Estudaram-se os mecanismos naturais que condicionaram o arrefecimento prolongado e extensivo, buscando-se identificar se há consenso entre diferentes autores, ou somente hipóteses divergentes, e estabelecer quais fatores climáticos estariam relacionados à PIG, além de: (a) determinar a contribuição de cada fator para a evolução climática e (b) explicar de que modo a circulação geral das esferas fluidas do Sistema Terra responde às forçantes climáticas ao longo do tempo. O tema tem interesse científico pela possibilidade de armazenar carbono em reservatórios naturais, para se alterar "a tendência atual ao efeito estufa" (Carneiro et al., 2004). A repercussões da paleoclimatologia (Oliveira et al., 2015) acentuam o interesse didático do tema, uma vez que as causas naturais da variação climática nem sempre são exploradas em obras didáticas (Carneiro et al., 2019). 


\section{Materiais e métodos}

A pesquisa envolveu: levantamento bibliográfico sobre Pequena Idade do Gelo e modelos de circulação atmosférica e anomalias térmicas; estudo acerca dos mecanismos naturais mais prováveis de alteração climática e respostas do Sistema Terra; revisão sobre aquecimento global e possibilidade de novos períodos de glaciação. Levantou-se extensa coletânea de artigos publicados e capítulos de livros sobre evolução climática holocênica: eventos de vulcanismo explosivo e mínimos de atividade solar nas anomalias climáticas em escalas de décadas e séculos. Na etapa final foram analisadas as possíveis anomalias climáticas da atualidade, buscando esclarecer aspectos controversos sobre aquecimento global antropogênico, sob o enfoque de Ciência do Sistema Terra.

\section{Resultados}

Eventos de intenso vulcanismo reduzem as temperaturas médias nos verões devido ao aumento na concentração de partículas, aerossóis e diversos gases na atmosfera. O bloqueio direto dos raios solares determina gradual resfriamento nos anos subsequentes a uma grande erupção. Vários autores (Miller et al., 2012; Briffa et al., 1998; Crowley et al., 2008; Gao et al., 2008; Schneider et al., 2009; Trigo et al., 2009; Wanner et al., 2011; Wegmann et al., 2014; Zhong et al., 2010) tendem a interpretar o vulcanismo como o fator climático mais provável para dar início à PIG. No entanto, o vulcanismo, isoladamente, não sustentaria séculos de resfriamento em grande extensão territorial. Portanto, embora uma sucessão de 50 anos de grandes erupções tropicais seja um "gatilho" para o arrefecimento do hemisfério Norte, seriam necessárias alterações na dinâmica dos oceanos e da atmosfera para preservar a alteração climática gerada na ejeção de gases e partículas na superfície. Nos últimos 8.000 anos a temperatura nos verões decresce linearmente no hemisfério Norte, pois o planeta estaria se distanciando do Sol, em escala bastante reduzida, sob taxa anual constante (Wanner et al., 2011). Porém, em todo o Holoceno, não se observaram expansões de geleiras no Ártico e em regiões montanhosas de baixas latitudes tão importantes quanto na PIG (Miller et al., 2012). Ademais, o vulcanismo, no século XIII e no período de 1600 a $1900 \mathrm{AD}$, foi muito evidente em relação à atualidade (Briffa \& Matheus, 2005, Crowley, 2000, Schneider et al.,
2009), tendo como referência diversas erupções tropicais no século XIX.

\section{Vulcanismo e a expansão do manto de gelo no Ártico}

Aerossóis vulcânicos de grandes erupções explosivas causam variações climáticas. Erupções explosivas, em geral associadas a magmas riolíticos, ricos em sílica, possuem grande conteúdo de gases dissolvidos na porção líquida. No interior da crosta os gases estão sob grande pressão e estão dissolvidos no magma. A extrusão libera os gases antes dissolvidos, que sofrem rápida expansão (Sutton, 1992). Piroclastos e gases expelidos da caldeira rapidamente se dissipam e as partículas mais frias (poeira, fumaça, aerossóis e bioaerossóis) são englobadas pela nuvem formada na erupção, ficando imersas na atmosfera. A parte superior da nuvem se comporta como uma pluma térmica, sofrendo convecção de materiais, a depender da densidade de cada um deles (Settle, 1978). As partes mais altas da nuvem são resfriadas à medida que a energia é dissipada para a atmosfera circundante. Em alguns eventos, nuvens atingem cerca de $50 \mathrm{~km}$ de altura, ou seja, quase o limite inferior da mesosfera. Os gases expelidos constituem-se principalmente por vapor de água, dióxido de carbono, dióxido de enxofre e ácido sulfídrico. São substâncias que reagem em contato com a atmosfera e geram aerossóis ácidos, tais como ácido sulfúrico, ácido fluorídrico e ácido clorídrico. Moléculas de $\mathrm{SO}_{2}$ são, provavelmente, as que promovem maiores alterações acima da tropopausa, pois ao interagir com moléculas de $\mathrm{OH}$ e $\mathrm{H}_{2} \mathrm{O}$, formam moléculas ácidas, como $\mathrm{H}_{2} \mathrm{SO} 4+\mathrm{H}_{2} \mathrm{O}$, que promovem aquecimento da alta troposfera, ao interceptar a radiação que entra, e resfriamento da baixa troposfera, por interceptar a radiação que sai do Sistema Terra (Schneider et al., 2011). A radiação solar é obstruída durante longo período de tempo pela poeira (cinza vulcânica) espalhada na alta atmosfera e moléculas aerossóis. Dependendo da magnitude do evento, a temperatura média global ou regional tende a diminuir; o fenômeno perdura até que as substâncias se dissipem. Admite-se ter havido 16 erupções vulcânicas que promoveram resfriamento entre 1630 e 1850 (Crowley et al., 2008). Em 1667, tiveram início erupções sucessivas, culminando em 1694 na intensa erupção tropical na Nova Guiné. O período mais frio da Pequena Idade do Gelo coincide com esta erupção tropical, que liberou enxofre na atmosfera, 
impedindo a penetração da radiação solar. Erupções explosivas promovem rápida expansão de gases na estratosfera (Fig. 1b) em direção aos polos, abrangendo extensas áreas de superfície em ambos os hemisférios (Gao et al., 2008).

Erupções vulcânicas em sequência, ocorrendo com intervalo de décadas, produzem resfriamento maior que uma única erupção de grande magnitude (Schneider, 2009). Após episódios de vulcanismo intenso, entre 1275 e 1450, sítios no Canadá tiveram significativo aumento na cobertura por gelo, permanecendo congelados até o presente, revelando a existência de mecanismos de resposta positivos ao resfriamento, ou seja, que manteriam a temperatura média semelhante àquela decorrente das erupções (Miller, 2012).

Estudos de Miller et al. (2012), Robock (2000) e Scheneider et al. (2009), sugerem uma correlação entre o decréscimo da linha de neve, a qual regula o volume e a ablação das geleiras, e a ocorrência de erupções explosivas. Porém, um evento explosivo apenas não tem efeito residual suficiente para alterar significativamente a linha de neve e a temperatura; seriam necessários sucessivos episódios, com hiato de décadas (Briffa et al. 1998). Estudos da variação da linha de neve e do balanço de massa em geleiras no Ártico (Koerner, 2005), em comparação com níveis atuais, se sustentam no fato de as geleiras e morainas serem os vestígios mais confiáveis da variação anual na temperatura dos verões. Foram estudados pequenos corpos de gelo, sob os quais se preservam vestígios de tundra do tempo de expansão das geleiras: a atividade de $\mathrm{C}^{14}$ foi aferida em 147 análises in situ, possibilitando comparar o período de depressão da linha de neve com o tempo presente (Miller et al., 2012).

A análise por radiocarbono de uma coleção de 94 vestígios de fauna, entre Islândia, Groenlândia e Canadá, com idade calibrada entre 800 e 2000 AD (altitude variável entre 500 a $1.200 \mathrm{~m}$ acima do nível do mar), resultou em uma função de densidade de probabilidade (f.d.p.), que reúne dados do Ártico interpretados em função da expansão das capas de neve (Fig. 1c). Os picos na f.d.p. exibiriam os períodos de maior depressão da linha de neve, evento que se relaciona à expansão de geleiras (Miller et al., 2012). Os dois principais intervalos observados para a redução da linha de neve $(\sim 1275 \mathrm{AD}, \sim 1450$ AD) coincidem com períodos de vulcanismo e de maiores emissões de gases sulfídricos na estratosfera em áreas setentrionais durante o Holoceno. Após episódios de vulcanismo, o Sistema Terra,

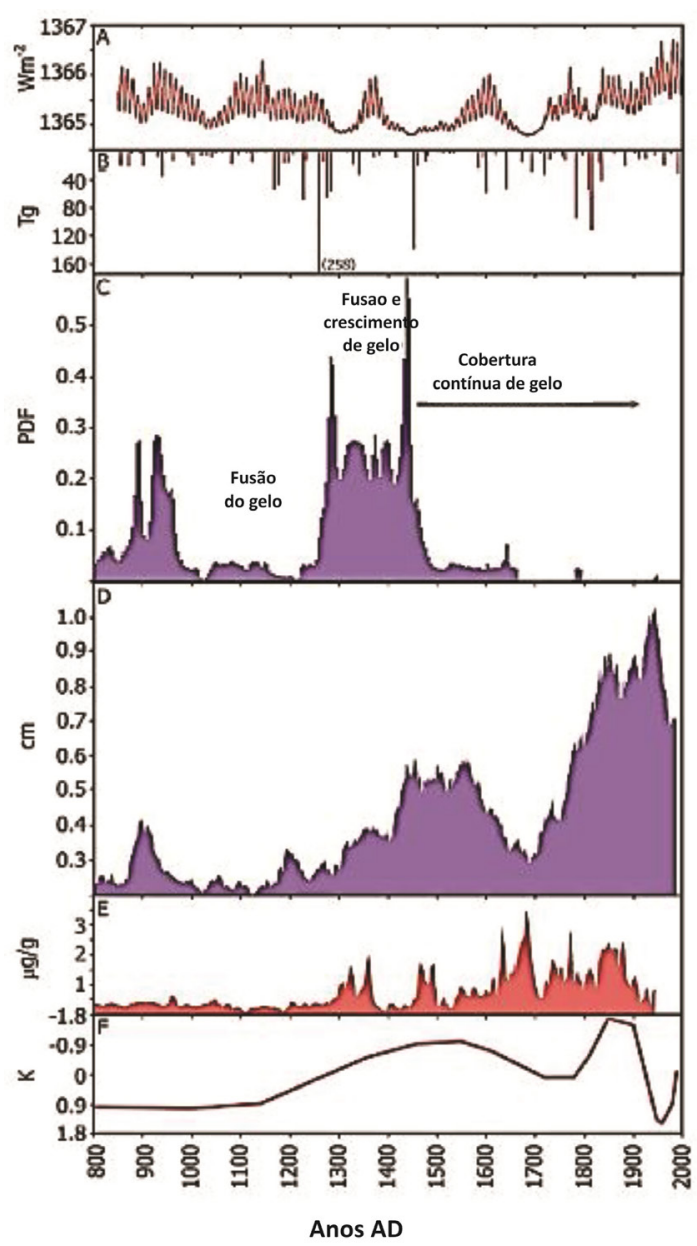

Figura 1. (A) Irradiância solar (Schmidt et al., 2001). (B) carga de aerossóis de sulfato na estratosfera, provenientes da atividade vulcânica (Gao et al., 2008). (C) Função de densidade de probabilidade para a expansão de geleiras no norte do Canadá, com base em análises de radiocarbono (Miller et al., 2012). (D) Espessura várvica de sedimentos em Hvítárvatn, na Islândia (Larsen et al., 2011). (E) Registro de geleiras na Islândia com enfoque para a expansão evidente em períodos de verões mais frios (Massé et al., 2008). (F) Variações de temperatura na região sul da Groenlândia (Dahl-Jensen et al., 1998). (Fonte: Modif. de Miller, 2012)

por intermédio dos oceanos, diminuiria a quantidade de calor transportada rumo ao norte em todo o Atlântico Norte em 0,04 PW', valor inferior ao esperado para o período 1300-1600 AD. Além disso, o albedo entre abril e setembro teria aumentado em latitudes superiores a $60^{\circ} \mathrm{N}$, em escalas próximas a 1,5 $\mathrm{Wm}^{-2}$ (Zhong et al., 2011). Para os dois períodos mencionados acima, existem ainda vestígios várvicos do fluxo de sedimentos depositados sobre condições de clima frio que sustentam

$1 \quad$ Petawatts: Um petawatt equivale a $10^{15}$ watts.

\begin{tabular}{c|c|c|c|c|c|}
\hline C Terrae Didat. & Campinas, SP & v.15 & $1-10$ & e019043 & 2019 \\
\hline
\end{tabular}


a hipótese de redução das temperaturas nos verões durante a PIG. Ritmitos do lago Hvítárvatn, na Islândia, constituídos por $8 \mathrm{~m}$ de sedimento consolidado, foram analisados por raios-X e difração a laser (Larsen et al., 2011). As análises indicam aumento da espessura dos ritmitos (Figs. 1d; 1e), em função de verões anomalamente frios, entre 1760 e 1820 AD como nunca antes observado em 2 $\mathrm{ka}$ (Larsen et al., 2011). A espessura diminuiria, em tese, no decorrer do século XX, com a regressão da geleira Langjökull, após intervalos de aquecimento abrupto. Algumas grandes erupções explosivas se destacam, no século XIX: uma situada em região tropical em 1909, não identificada na literatura; no Monte Tambora, Indonésia (1815), nas Filipinas (1831), e Nicarágua (1831). Tambora coincidiu com o Mínimo Solar de Dalton (Fig. 2), sendo considerado evento Super-Colossal, no Índice de Explosividade Vulcânica, uma escala que não tem limite superior. As duas últimas, embora menos intensas, apresentam curto intervalo de tempo entre si e afetaram o clima regional. $\mathrm{O}$ oceano não se recuperou por completo do resfriamento causado pela erupção de 1909 (Crowley, 2008). Erupções tropicais exercem maior efeito no clima global do que aquelas de latitudes mais elevadas. Aerossóis ácidos de erupções polares se dissipam rapidamente da estratosfera, pois o vórtex, resultante dos ciclones nas regiões polares, promove subsidência dos gases e moléculas na alta atmosfera (Schneider et

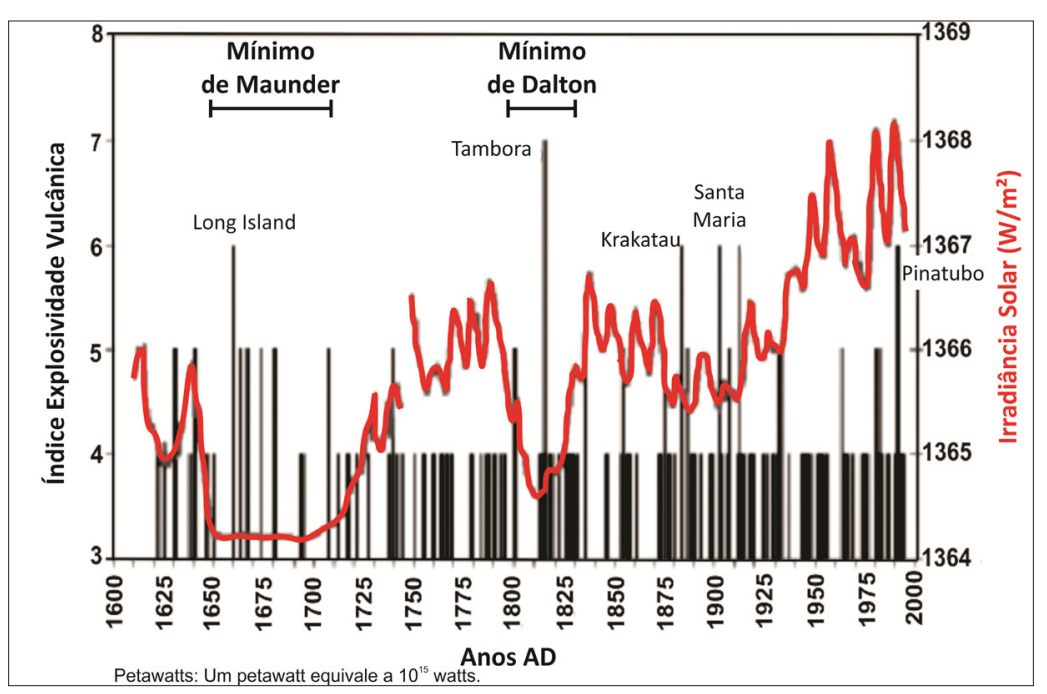

Figura 2. Diagrama relacionando a Irradiância solar (Lean et al., 1995) com o índice de explosividade vulcânica (VEI) dos últimos quatro séculos, extraído de www.volcano.si.edu (Smithsonian Institution, 2017). A imagem mostra que eventos de atividade vulcânica intensa podem coincidir com mínimos de irradiância, tendo como exemplo a simultaneidade aproximada entre a erupção do Monte Tambora e o Mínimo de Dalton em análise multiproxy (Fonte: Modif. de Trigo et al., 2009) al., 2009). As erupções tropicais guardam relação direta com anomalias térmicas do Holoceno.

A erupção do Monte Tambora, em 1815, na ilha de Sumbaya (Indonésia), é muito presente na literatura talvez por representar um dos maiores impactos naturais sobre o homem na Idade Moderna. Milhares de mortes foram registradas e o efeito da erupção se alastrou por todo o planeta nos anos subsequentes (Wood, 2014). As regiões do globo com vulcanismo ativo são hoje amplamente monitoradas, o que mostra cautela crescente dos pesquisadores em evitar tragédias como aquela na Indonésia. Após a erupção de Tambora, 1816 é conhecido como o "ano sem verão" na Europa. A grande emissão de $\mathrm{SO}_{2}$ na atmosfera, convertida em aerossóis de sulfato na estratosfera, acima dos $15 \mathrm{~km}$ de altitude, promoveu queda (em relação ao século XX) de 2 a $4{ }^{\circ} \mathrm{C}$ no Mediterrâneo, oeste e centro da Europa, nos meses de junho, julho e agosto (Luterbacher \& Pfister, 2015). A porção leste e oeste da Rússia, e leste da Escandinávia mostraram comportamento climático regular. A precipitação no verão de 1816 foi anômala (Trigo, 2009). Ainda em 1817, a circulação atmosférica permaneceu desregulada. Mais zonas de baixa pressão foram registradas, levando chuvas incessantes e frentes frias ao oeste e centro da Europa, com perdas na agricultura e fome na Europa Ocidental. Subsistem hipóteses que consideram as zonas de ciclone como decorrência das monções de verão asiáticas, que decresceram de intensidade na década (Wegmann, 2014). Uma onda migratória, associada à miséria na Europa, levou importante contingente populacional a cruzar o Atlântico, superlotando, durante alguns anos, a costa norte-americana. Evidências embasam não apenas a redução das temperaturas nos verões, mas também o aumento destas durante os invernos subsequentes a eventos de vulcanismo. Análises e simulações para as dez maiores erupções explosivas tropicais, entre 1769 e $2000 \mathrm{AD}$, estimam um forte gradiente de calor adentrando a Europa, especialmente na Europa Ocidental e no Atlântico Norte, fato que se relaciona à fase positiva da NAO (North

\begin{tabular}{c|c|c|c|c|c}
\hline (C) Terrae Didat. & Campinas, SP & v.15 & $1-10$ & $\mathrm{e} 019043$ & 2019 \\
\hline
\end{tabular}


Atlantic Oscillation), anomalia climática típica da PIG (Fischer et al., 2007) discutida adiante. No entanto, alguns autores atribuem tal aquecimento ao El Niño. As simulações indicam que a anomalia térmica, nos invernos, subsequente à fase positiva da NAO, foi mais intensa em 1817 que em 1816 (Fischer et al., 2007). É necessário um hiato para que o gradiente térmico se estabeleça por completo. O inverno de 1817 foi, portanto, mais quente que no ano anterior, sendo, por exemplo, $3^{\circ} \mathrm{C}$ mais quente na Escandinávia (Trigo et al., 2009). Alguns autores consideram o século XIII como o início efetivo da PIG, porque houve importantes erupções entre 1250 e $1300 \mathrm{AD}$, tanto nos trópicos quanto nas altas latitudes (Schneider et al., 2009). Um modelo climático criado para simulações atmosféricas do século XX, o CCSM3 (Community Climate System Model, Version 3), foi adaptado para pesquisas acerca das dinâmicas terrestres que promovem resfriamento a partir de erupções no intervalo de 1250-1300 AD, tendo como base elementos como ofeedback dos oceanos, mantos de gelo e atmosfera (Collins et al., 2006). A adaptação do CCSM3 para áreas de continente e atmosfera com grids de $2,8 \mathrm{x}$ $2,8^{\circ}$ (latitude/longitude), e para oceanos e geleiras com grids horizontais de $1 \times 1^{\circ}$, para tornar mais eficaz a reconstrução paleoclimática.

Schneider et al. (2009) interpretaram concentrações de sulfato nos polos como indicadores de erupções no século XIII (Tab. 1), com início em áreas tropicais e continuidade nas altas latitudes, convertendo os dados de concentração de $\mathrm{SO}_{2} \mathrm{em}$ escala de tempo e latitude, tendo como período de controle a simulação de concentração de sulfato em um período pré-industrial de 50 anos, descrito por Amman et al. (2007), similar ao modelo de Gao et al. (2008). As simulações com o CCSM3 evidenciam a alteração climática para a temperatura da superfície, nível de pressão do mar, precipitação e perfis de variação da temperatura na atmosfera e nos ventos zonais. O experimento permite comparar efeitos de erupções nos polos com aqueles nos trópicos.

Ainda por intermédio do CCSM3 existem estimativas de causas prováveis para mudanças nos padrões de precipitação atmosférica. Foi observada uma tendência de redução na precipitação durante os verões, pois a radiação solar seria interceptada pelos aerossóis. As secas resultantes não se limitariam aos continentes, mas em vastas áreas oceânicas a partir de $10^{\circ} \mathrm{N}$. Dados de proxy indicam uma restrição na migração da ZCIT (Zona de Convergência Intertropical) rumo ao hemisfério de verão, pois estaria havendo mais arrefecimento nas baixas e médias latitudes deste, do que nas baixas e médias latitudes do hemisfério de inverno (Schneider et al., 2009). Estes padrões climáticos corresponderiam a uma contração das células de Hadley e um decréscimo de monções.

\section{Simulações paleoclimáticas da variação da atividade solar}

É comum a divergência entre especialistas quanto a possíveis mecanismos forçantes de eventos ou anomalias climáticas durante o Holoceno, tendo como referência especialmente a Pequena Idade do Gelo (PIG) e, antes desta, o Período Quente Medieval (PQM). Por vezes os dados de proxy utilizados são muito escassos ou esparsos. O parâmetro aplicado às funções varia entre autores, sendo ora análises em troncos de arvores, ora datação de isótopos cosmogênicos. Outro elemento que dificulta o consenso entre especialistas se relaciona aos vários fatores de correção utilizados em suas fórmulas e simulações, que alteraria a escala de tempo e a precisão das incertezas nas diferentes reconstruções paleoclimáticas. As medições de Mann (Mann et al., 1999) apresentam, por exemplo, grande número de dados por unidade de tempo, sendo, no entanto, pouco heterogêneas (Crowley, 2000). Hoje, a reconstituição paleoclimática do Holoceno se baseia na análise conjunta de proxys incluídas em estudos de distintos domínios do conhecimento (como análises dendrocronológicas, datações por radiocarbono, sedimentos glaciais, recifes de corais e até mesmo registros de atividade solar de séculos passados). A temperatura da superfície do planeta foi estimada, em uma

Tabela 1. Datas de erupções e massa estimada de aerossol ácido, em Mt (Fonte: Modif. de Schneider et al., 2009)

\begin{tabular}{|c|c|c|c|c|}
\hline & $\begin{array}{l}\text { Data de erupção } \\
\text { tropical }\end{array}$ & $\begin{array}{c}\text { Pico de massa de aerossol } \\
\text { de erupção tropical }\end{array}$ & $\begin{array}{l}\text { Data de erupção } \\
\text { de alta latitude }\end{array}$ & $\begin{array}{l}\text { Pico de massa de aerossol } \\
\text { de erupção de alta latitude }\end{array}$ \\
\hline Evento 1 & Outubro 1257 & 200 & Abril 1258 & 124 \\
\hline Evento 2 & Janeiro 1269 & 40 & Maio 1269 & 25 \\
\hline Evento 3 & Janeiro 1278 & 75 & Março 1278 & 47 \\
\hline Evento 4 & Abril 1286 & 40 & Julho 1286 & 25 \\
\hline \multicolumn{2}{|c|}{ (c) Terrae Didat. } & Campinas, SP & \begin{tabular}{l|l} 
& $1-10$ \\
\end{tabular} & \begin{tabular}{|l|} 
\\
\end{tabular} 019043 \\
\hline
\end{tabular}


escala de 1500 anos, por Mann (2009, p. 1256) no esforço de unir informações paleoestratigraficas e dendrocronológicas para compreender a evolução do clima no decorrer do tempo, com enfoque na PIG e no PQM. A resolução temporal dessa simulação é decadal, sem influência de variações climáticas pontuais e anuais. As reconstruções feitas para a PIG e PQM são mais confiáveis e precisas para o hemisfério Norte. Para o PQM, o padrão presente na temperatura da superfície sugere, em relação às condições climáticas atuais, aquecimento, no período entre 950 a $1250 \mathrm{AD}$, em partes do Atlântico Norte, sul da Groenlândia, ártico da Eurásia e partes da América do Norte (Mann et al., 2009). Vale ressaltar, em específico na Eurásia, que o padrão de aquecimento encontrado corresponde fortemente ao padrão La Niña, no Oceano Pacífico Central (com águas mais quentes a oeste e mais amenas a leste).

A precisão dos modelos, se analisada no decorrer dos séculos, prova que a forçante solar de maior magnitude não estaria associada a grandes eventos de mudança climática. Porém, de baixa a média escala de forçante, a radiação solar alteraria o clima de um hemisfério em escala de tempo de décadas, atenuando os efeitos de arrefecimento vulcânico, em determinados períodos da história, tendo como exemplo o Mínimo de Maunder (estando contido nele o ciclo de onze anos de Schwabe, Miyake et al., 2013). A forçante solar, que é abruptamente acrescida entre o final do século XVI e início do XVII, mostra-se pouco relevante, pois é simultânea a um período relacionado, preponderantemente, ao resfriamento pela ação vulcânica (Ammann et al., 2007). Portanto, a forçante solar poderia se relacionar, no decorrer das décadas, a alteração na dinâmica interna das nuvens e a quantia estratosférica de $\mathrm{O}^{3}$. Para obter tal conclusão apenas modelos mais sensíveis à flutuação térmica devem ser utilizados, pois a proxy em si é esparsa e depende da precisão na análise. A variação descrita acima relaciona-se ao balanço de radiação entre as ondas curtas (espectro visível) que adentram a atmosfera e as ondas longas $(10 \mu \mathrm{m})$ refletidas da terra. Alterações na absorção atmosférica do ultravioleta (UV) e infravermelho de ondas próximas (IR) alteram o balanço energético do planeta, assim como a absorção e espalhamento da radiação dentro da troposfera. A dinâmica dos ciclos orbitais, como a precessão dos equinócios, tem durante a PIG menor influência nas anomalias térmicas e maior importância na alteração das monções do Pacífico e em deslocamentos da Zona de
Convergência Intertropical (ZCI), sendo, portanto discutida no tópico seguinte.

\section{Alterações nos padrões gerais de circulação e expansão de geleiras no Ártico}

Uma possível justificativa para a controvérsia entre climatologistas em definir o início e o término da PIG é que esta não ocorreu simultaneamente em todo o hemisfério Norte. Existem registros para expansão de geleiras na Escandinávia, que teriam durado até $1920 \mathrm{AD}$ (Nesje \& Dahl, 2003), o que dificultaria ainda mais as comparações inter-regionais para eventos de resfriamento. Alguns consideram os séculos XIII e XIV como parte da PIG, pois houve significativos eventos de resfriamento e expansão de geleiras (Briffa \& Matheus, 2005). O fato é que após o período medieval, marcado por temperaturas elevadas, houve intercalação de períodos de arrefecimento na Europa, América e Ásia, que não estariam, contudo, em sincronia. As análises disponíveis para geleiras por dendrocronologia ou datação por radiocarbono possuem acurácia de \pm 100 anos e confiabilidade de 95\% (Briffa \& Matheus, 2005). Datações feitas nos Alpes permitem sustentar hipóteses confiáveis para períodos em que as geleiras atingiram sua maior extensão, possibilitando até mesmo indicar que em 1350, 1650 e 1850 AD mantos de gelo avançaram por extensão aproximadamente similar nos Alpes suíços (Holzhauser, 1997).

Existem dúvidas quanto às causas das grandes expansões de gelo. Embora a redução de temperaturas nos verões seja uma hipótese tentadora, é mais provável que o aumento da precipitação atmosférica nos invernos justifique os eventos de expansão. Comparações entre o índice NAO (North Atlantic Oscillation) e as curvas de balanço frontal de duas geleiras, Nigardsbreen e Briksdalsbreen, ambas em Jostedalsbreen (Noruega), sugerem que o balanço de massa das geleiras estaria associado a invernos rigorosos, com avanço anual máximo de $80 \mathrm{~m}$ (Jones et al., 1997). As observações foram feitas durante a década de 1990, porém ajudam a entender como grandes extensões de gelo funcionariam em tempos pretéritos. Para elucidar tal comportamento típico aos invernos é necessário explicar o modo de variabilidade climática NAO da pressão ao nível do mar no Norte Atlântico. Nos invernos, há um contraste meridional de pressão caracterizado por uma zona de ciclone centrada na Islândia e uma de anti- 
ciclone na região dos Açores (Atlântico Nordeste). Tal gradiente desloca correntes de ar e tempestades de inverno, em médias latitudes, de oeste a leste no Atlântico Norte, que transporta ventos brandos e úmidos ao Noroeste europeu, causando, porém, alterações regionais na precipitação atmosférica, identificadas na fase positiva e negativa da NAO. A chamada fase positiva do índice NAO remete à precipitação acima do normal na Islândia, Reino Unido, e Escandinávia e abaixo do normal nas porções central e sul da Europa, Mediterrâneo e Noroeste da África (Nesje \& Dahl, 2002). O padrão corresponde a forte anticiclone na região dos Açores, próximo à latitude $35^{\circ} \mathrm{N}$. A fase negativa NAO corresponderia a um fraco anticiclone em Açores, invertendo o padrão de precipitação, permitindo invernos mais chuvosos ao sul da Europa.

A precipitação nos invernos no noroeste da Noruega, entre 1865 e 1995 AD, mostra forte correlação $(r=+0,77)$ com o índice NAO (Hurrell, 1995), lembrando que períodos prolongados de anomalias atmosféricas relacionadas ao NAO mudam a quantidade de calor que a atmosfera retira dos oceanos assim como o derretimento do gelo nos oceanos. As variações no mesmo índice remetem também ao balanço de massa em geleiras na Escandinávia, cuja fase positiva ocasionaria aumento de precipitação nessas geleiras e redução nas geleiras dos Alpes (Reichert et al., 2001), resultando em padrão de balanço positivo de massa a norte, simultaneamente a um padrão negativo a sul. Para explicar o avanço de geleiras na Noruega (Escandinávia), Nesje \& Dahl (2003) compararam séries de temperatura da Inglaterra em 1659 com séries de temperatura de Bergan (Noruega), que possuem boa correlação $(\mathrm{r} \sim 0,8)$, para testar quais os mecanismos sazonais suscitariam eventos de congelamento. Os invernos frios e com elevada precipitação ficaram evidentes, na análise dos registros, para o final do século XVII e início do XVIII (Manley, 1974). Ademais, as series de temperatura para os verões, assim como reconstruções térmicas a partir de anéis de árvores, não indicaram que o arrefecimento nos verões proporcionaria condições suficientemente frias para justificar o avanço de geleiras. Pelo contrário, os verões estariam se tornando, segundo as reconstruções, mais quentes no mesmo período. Ou seja, prevaleceria a precipitação nos invernos como causa de avanços mais significativos do gelo na Europa.

O padrão NAO seria, em hipótese, capaz de explicar porque a expansão de geleiras não ocor- reu com simultaneidade pela Europa. Geleiras na Escandinávia teriam se expandido durante os invernos dos anos 1990, no aumento da precipitação relacionado ao índice de oscilação do Atlântico Norte. Contudo, nos Alpes, as geleiras teriam perdido de 30 a $40 \%$ de sua superfície e $50 \%$ de seu volume, no mesmo período (Reichert et al., 2001). Ou seja, o dipolo meridional ocasionado por este índice de variação da pressão atmosférica, pode ser uma causa pela qual a PIG atingiu primeiramente áreas polares, para posteriormente se estender em direção ao trópico Norte. Alterações desta magnitude tendem a mostrar que mesmo o Holoceno, um intervalo de tempo tomado de estabilidade geológica, possui alguma instabilidade, mesmo que em escala moderada.

Embora a expansão de mantos de gelo tenha tido redução na Europa durante o século XVIII, áreas a norte da Ásia se mostraram, em tese, bastante frias. As anomalias térmicas negativas seriam da escala de $0,8^{\circ} \mathrm{C}$, em média, para o período de 1811 a 1840 AD. A América do Norte estaria em fase com a Ásia, com resfriamento durante o século XVIII (Briffa \& Matheus, 2005), mostrando que os eventos da PIG ocorreram, de fato, em distintos continentes e países por todo o hemisfério Norte. Porém não só a NAO está associada à PIG. Importantes anomalias teriam ocorrido no Pacífico e Leste asiático. Há correlações comprovadas dos parâmetros orbitais do Sol e da Terra que, associados ao vulcanismo do Holoceno e ao Mínimo de Maunder (redução de $0,65 \%$ da insolação), ajudam a explicar alterações nos modelos de circulação geral durante a PIG, sendo necessário elucidar qual o potencial de alteração climática dos ciclos orbitais. A insolação recebida pela Terra depende não somente de alterações de fluxo de calor no Sol, mas também dos parâmetros orbitais, como o ciclo de precessão dos equinócios que produz anomalias de insolação. Se a radiação é favorecida no hemisfério Norte, a Zona de Convergência Intertropical (ZCI) tende a migrar mais a norte da zona equatorial no verão (Yan et al., 2015). Diferentemente dos parâmetros orbitais, as consequências das alterações de fluxo de energia no Sol e irradiância são simétricas nos dois hemisférios. Assim, é mais provável que migrações da ZCI estejam sincronizadas às variações dos parâmetros orbitais, ocorrendo de Norte a Sul. Existem hipóteses para uma grande contração meridional da ZCI, das monções de verão do leste asiático (MVLA) e das monções de verão da Austrália (MVA) durante a PIG, tendo como base 
registros paleo-hidrológicos do Leste Asiático e da Austrália (Yan et al., 2015). O padrão estaria associado não somente a alterações orbitais ligadas à precessão, mas também ao vulcanismo explosivo intenso no Pacífico Oeste e às reduções de insolação, estimadas em, no máximo, 0,65\% (Ammann et al., 2007), conforme simulações realizadas com o NCAR. Uma redução nas monções de verão durante a PIG teria ocorrido, simetricamente em ambos os hemisférios, com secas consideráveis nos anos de 1460, 1685 e $1800 \mathrm{AD}$, sendo que tais períodos coincidem com três mínimos de atividade solar, respectivamente, Mínimo de Spörer, Mínimo de Maunder e Mínimo de Dalton. Experimentos com o modelo climático CCSM3 confirmaram tais conclusões e sugerem importante redução na precipitação na região norte do continente australiano. As monções de verão, devido à maior amplitude térmica dos continentes em relação aos oceanos, geram aumento da circulação de monções e da precipitação. Na PIG, a menor irradiância solar nos verões teria reduzido o padrão de monções no Pacífico (Yan et al., 2015). Em geral, sugere-se fortalecimento da circulação de Walker, no Pacífico tropical, durante a PIG, com maior precipitação na região do Indo-Pacífico, além de comportamento similar ao El-Niño (Cobb et al., 2003), em relação aos padrões hidrológicos.

\section{Conclusões}

A anomalia climática da Pequena Idade do Gelo dispersou-se em escalas de espaço e tempo, deflagrada por eventos de vulcanismo tropical explosivo intenso associados a períodos de menor atividade na superfície do Sol. O tema desperta grande interesse didático. O fenômeno revela como uma forçante interna (vulcanismo), atenuada por um evento externo (mínimos de atividade solar), em interação com processos do Sistema Terra pode promover arrefecimento, com expansão importante de mantos de gelo. Os modelos de circulação geral e de dinâmicas como a NAO (North Atlantic Oscillation) mostram como o planeta responde às forçantes naturais. Trocas de energia e o equilíbrio físico nas esferas fluidas podem manter, durante séculos, as condições térmicas provenientes de eventos catastróficos, como grandes erupções simultâneas à contração da ZCI (Zona de Convergência Intertropical) e das monções no Pacífico. O clima é determinado pelos ciclos orbitais que controlam a ciclicidade de períodos glaciais e interglaciais e influenciam a alteração do funcionamento da ZCI. Isoladamente, porém, a atividade solar é incapaz de ocasionar eventos como a PIG. O vulcanismo seria o "gatilho" mais provável para anomalias climáticas de resfriamento não linear do planeta. As variações da circulação geral do planeta sobre o oceano Pacífico e a fase positiva da NAO teriam conservado o arrefecimento promovido por eventos vulcânicos em termos de décadas. Os mínimos de Dalton e de Maunder teriam agravado o arrefecimento em períodos específicos, como no século XVI.

\section{Agradecimentos}

Os autores agradecem ao Conselho Nacional de Desenvolvimento Científico e Tecnológico, CNPq, pela concessão das bolsas de Iniciação Científica do Programa de Bolsas de Iniciação Científica (PIBIC), e pela concessão de Bolsa de Produtividade em Pesquisa, nível 2, ao primeiro autor (CDRC).

\section{Referências}

Ammann, C. M.; Joos, F.; Schimel, D. S.; Otto-Bliesner, B. L.; \& Tomas, R. A. (2007). Solar influence on climate during the past millennium: Results from transient simulations with the NCAR Climate System Model. Proceedings of the National Academy of Sciences, 104(10), 3713-3718.

Briffa, K. R. \& Matthews, J. A. (2005). The 'Little Ice Age': Re-evaluation of an evolving concept. Geografiska Annaler: Series A, Physical Geography, 87(1), 17-36.

Briffa, K. R.; Jones, P. D.; Schweingruber, F. H.; \& Osborn, T. J. (1998). Influence of volcanic eruptions on Northern Hemisphere summer temperature over the past 600 years. Nature, 393(6684), 450455.

Carneiro, C. D. R.; Freitas, G. B. F. de; Franco, L. M.; \& Gonçalves, P. W. (2018). O que a Pequena Idade do Gelo pode nos ensinar sobre mudança climática? In: Carneiro, C.D.R.; Gonçalves P.W.; Imbernon, R.A.L.; Machado, F.B.; Cerri, C.A.D. (Eds.) (2018). Ensino e História de Ciências da Terra. Campinas: Soc. Bras. Geol. p. 260-265. URL: http:// www.ige.unicamp.br/geoscied2018/pt/trabalhos/. (Anais VIII Simp. Nac. Ens. Hist. Ciências da Terra / EnsinoGEO-2018 - Geociências para todos. Campinas, SBGeo, 2018). (ISBN 978-85-9919821-6).

Carneiro, C. D. R.; Freitas, G. B. F. de; Franco, L. M.; \& Gonçalves, P. W. (2019). A Pequena Idade do Gelo: evidências históricas e geológicas de mudanças climáticas. Revista Geonomos. (Submetido em 
28.ago.2019).

Carneiro, C. D. R.; Toledo, M. C. M.; \& Almeida, F. F. M. de. (2004). Dez motivos para a inclusão de temas de Geologia na educação básica. Rev. Bras. Geoc., 34(4), 553-560. doi: 10.25249/03757536.2004344553560

Cobb, K. M.; Charles, C. D.; Cheng, H.; \& Edwards, R. L. (2003). El Nino/Southern Oscillation and tropical Pacific climate during the last millennium. Nature, 424(6946), 271-276.

Collins, W. D.; Bitz, C. M.; Blackmon, M. L.; Bonan, G. B.; Bretherton, C. S.; Carton, J. A.; ... \& Kiehl, J. T. (2006). The community climate system model version 3 (CCSM3). Journal of Climate, 19(11), 2122-2143.

Crowley, T. J. (2000). Causes of climate change over the past 1,000 years. Science, 289(5477), 270-277.

Crowley, T. J.; Zielinski, G.; Vinther, B.; Udisti, R.; Kreutz, K.; Cole-Dai, J.; \& Castellano, E. (2008). Volcanism and the little ice age. PAGES news, 16(2), 22-23.

Dahl-Jensen, D.; Mosegaard, K.; Gundestrup, N.; Clow, G. D.; Johnsen, S. J.; Hansen, A. W.; \& Balling, N. (1998). Past temperatures directly from the Greenland ice sheet. Science, 282(5387), 268-271.

Fischer, E. M.; Luterbacher, J.; Zorita, E.; Tett, S. F. B.; Casty, C.; \& Wanner, H. (2007). European climate response to tropical volcanic eruptions over the last half millennium. Geophysical Research Letters, 34, L05707. doi: 10.1029/2006GL027992.

Gao, C.; Robock, A.; \& Ammann, C. (2008). Volcanic forcing of climate over the past 1500 years: An improved ice core based index for climate models. Journal of Geophysical Research: Atmospheres, 113, D23. doi: 10.1029/2008JD010239.

Holzhauser, H. (1997). Fluctuations of the Grosser Aletsch Glacier and the Gorner Glacier during the last 3200 years: new results. Glacier fluctuations during the Holocene. Akademie der Wissenschaften und der Literatur, 35-58.

Hurrell, J. W. (1996). Decadal trends in the North Atlantic Oscillation: regional temperatures and precipitation. Oceanographic Literature Review, 2(43), 116.

Jones, P. D.; Jonsson, T.; \& Wheeler, D. (1997). Extension to the North Atlantic Oscillation using early instrumental pressure observations from Gibraltar and South-West Iceland. Intern. J. Climatology, 17(13), 1433-1450.

Jones, P.D.; \& Bradley, R.S. (1992). Climatic variations over the last 500 years. In Bradley, R.S.; Jones, P.D. (Eds.) (1992). Climate since AD 1500. London and New York: Routledge, p. 649-65.

Koerner, R. M. (2005). Mass balance of glaciers in the Queen Elizabeth Islands, Nunavut, Canada. $A n-$ nals of Glaciology, 42(1), 417-423.

Larsen, D. J.; Miller, G. H.; Geirsdóttir, Á.; \& Thord- arson, T. (2011). A 3,000-year varved record of glacier activity and climate change from the proglacial lake Hvítárvatn, Iceland. Quaternary science reviews, 30(19), 2715-2731.

Lean, J.; Beer, J.; \& Bradley, R. (1995). Reconstruction of solar irradiance since 1610: Implications for climate change. Geophysical Research Letters, 22, 31953198. doi: 10.1029/95g103093.

Luterbacher, J.; \& Pfister, C. (2015). The year without a summer. Nature Geoscience, 8(4), 246-248.

Manley, G. (1974). Central England temperatures: monthly means 1659 to 1973. Quarterly Journal of the Royal Meteorological Society, 100(425), 389-405.

Mann, M. E. (2002). Little Ice Age. Encyclopedia of global environmental change, 1, 504-509.

Mann, M. E.; Bradley, R. S.; \& Hughes, M. K. (1999). Northern hemisphere temperatures during the past millennium: inferences, uncertainties, and limitations. Geophysical Research letters, 26(6), 759762.

Mann, M. E.; Zhang, Z.; Rutherford, S.; Bradley, R. S.; Hughes, M. K.; Shindell, D.; Ammann, C.; Faluvegi, G. \& NI, F. (2009). Global signatures and dynamical origins of the Little Ice Age and Medieval Climate Anomaly. Science, 326(5957), 1256-1260.

Massé, G.; Rowland, S. J.; Sicre, M. A.; Jacob, J.; Jansen, E.; \& Belt, S. T. (2008). Abrupt climate changes for Iceland during the last millennium: evidence from high resolution sea ice reconstructions. Earth and Planetary Science Letters, 269(3), 565-569.

Miller, G. H.; Geirsdóttir, Á.; Zhong, Y.; Larsen, D. J.; Otto Bliesner, B. L.; Holland, M. M.; ... \& Anderson, C. (2012). Abrupt onset of the Little Ice Age triggered by volcanism and sustained by sea-ice/ ocean feedbacks. Geophysical Research Letters, 39, L02708. doi: 10.1029/2011gl050168.

Miyake, F.; Masuda, K.; \& Nakamura, T. 2013. Lengths of Schwabe cycles in the seventh and eighth centuries indicated by precise measurement of carbon-14 content in tree rings. J. Geophys. Res.: Space Physics, 118, 7483-7487. doi: 10.1002/2012JA018320.

Nesje, A.; \& Dahl, S. O. (2003). The 'Little Ice Age'only temperature? The Holocene, 13(1), 139-145. doi: 10.1191/0959683603hl603fa.

Oliveira, M. J.; Baptista, G. M. M.; Carneiro, C. D. R.; \& Vecchia, F. A. S. (2015). História geológica e Ciência do clima: Métodos e origens do estudo dos ciclos climáticos na Terra. Terra, 12(1), 03-26. URL: http://www.ige.unicamp.br/terrae/V12/T V12 1.html.

Reichert, B. K.; Bengtsson, L.; \& Oerlemans, J. (2001). Midlatitude forcing mechanisms for glacier mass balance investigated using general circulation models. Journal of Climate, 14(17), 3767-3784.

Robock, A. (2000). Volcanic eruptions and climate. Reviews of Geophysics, 38(2), 191-219.

\begin{tabular}{c|c|c|c|c|c}
\hline (C) Terrae Didat. & Campinas, SP & v.15 & $1-10$ & $\mathrm{e} 019043$ & 2019 \\
\hline
\end{tabular}


Schmidt, G. A.; Shindell, D. T.; \& Tsigaridis, K. (2014). Reconciling warming trends. Nature Geoscience, 7(3), 158-160.

Schneider, D. P.; Ammann, C. M.; Otto-Bliesner, B. L.; \& Kaufman, D. S. (2009). Climate response to large, high-latitude and low-latitude volcanic eruptions in the Community Climate System Model. Journal of Geophysical Research: Atmospheres, 114, D15. doi: 10.1029/2008JD011222.

Settle, M. (1978). Volcanic eruption clouds and the thermal power output of explosive eruptions. Journal of Volcanology and Geothermal Research, 3(3), 309324.

Shindell, D. T.; Schmidt, G. A.; Mann, M. E.; Rind, D.; \& Waple, A. (2001). Solar forcing of regional climate change during the Maunder Minimum. Science, 294(5549), 2149-2152.

Smithsonian Institution. (2017). Database search on volcanoes of the world and their eruptions. Smithsonian Institution http://volcano.si.edu/search_eruption.cfm

Sutton, A. J.; McGee, K. A.; Casadevall, T. J.; \& Stokes, B. (1992). Fundamental Volcanic-Gas-Study Techniques: An Integrated Approach to Monitoring. In: Monitoring Volcanoes: Techniques and Strategies used by the staff of the Cascades Volcano Observatory, 181(1966), 1980-90.

Trigo, R. M.; Vaquero, J. M.; Alcoforado, M. J.; Bar- riendos, M.; Taborda, J.; García Herrera, R.; \& Luterbacher, J. (2009). Iberia in 1816, the year without a summer. Intern. J. Climatology, 29(1), 99-115.

Wanner, H.; Solomina, O.; Grosjean, M.; Ritz, S. P.; \& Jetel, M. (2011). Structure and origin of Holocene cold events. Quaternary Science Reviews, 30(21), 3109-3123. doi: 10.1016/j.quascirev.2011.07.010.

Wegmann, M.; Brönnimann, S.; Bhend, J.; Franke, J.; Folini, D.; Wild, M.; \& Luterbacher, J. (2014). Volcanic influence on European summer precipitation through monsoons: possible cause for "Years without Summer" ${ }^{*}$. Journal of Climate, 27(10), 3683-3691. doi: 10.1175/JCLI-D-13-00524.1.

Wood, G. D. A. (2014). Tambora: the eruption that changed the world. Princeton University Press.

Yan, H.; Wei, W.; Soon, W.; An, Z.; Zhou, W.; Liu, Z.; ... \& Carter, R. M. (2015). Dynamics of the intertropical convergence zone over the western Pacific during the Little Ice Age. Nature Geoscience, 8(4), 315-320.

Zhong, Y.; Miller, G. H.; Otto-Bliesner, B. L.; Holland, M. M.; Bailey, D. A.; Schneider, D. P.; \& Geirsdottir, A. (2011). Centennial-scale climate change from decadally-paced explosive volcanism: a coupled sea ice-ocean mechanism. Climate Dynamics, 37(11-12), 2373-2387. doi: 10.1007/s00382010-0967-z. 